\title{
ANALISIS POTENSI PANAS BUMI DENGAN METODE GEOMAGNET DI DAERAH GEDONG SONGO UNGARAN JAWA TENGAH
}

\author{
FATIMAH \\ Jurusan Teknik Geologi \\ "Nasional" College of Technology Yogyakarta \\ Sekolah Tinggi Teknologi Nasional Yogyakarta \\ Jl. Babarsari, Caturtunggal, Depok, Caturtunggal, Depok, Sleman, Yogyakarta 55281 \\ fatim_miharna@yahoo.com
}

\begin{abstract}
Geothermal is a renewable and sustainable energy that can be used to replace fossil energy in the future. Indication of geothermal systems is usually characterized by the appearance of surface manifestations, the presence of hot springs and fumaroles in the area of Mount Ungaran is a strong indication of geothermal potential beneath the surface. This research was conducted to determine geothermal energy below surface and to model geothermal system based on geological, geochemical and geomagnetic survey. Geology of Ungaran is composed by Tertiary volcanic rock from the Miocene to the Pleistocene, presumably a heat source in Ungaran Holocene age. The structure at Ungaran is controlled by a fault that leads to the southwest - northeast, so that the liquid and steam from the reservoir exit through the weak zone and appear on the surface. From Geomagnetic maps showing low magnetic levels ranging from -185 to $-3.3 n$ T interpreted as a heat source in Ungaran, the distribution of heat sources extends north of Gedongsongo.

Keyword: Gedong Songo, Geothermal, Magnetic
\end{abstract}

\begin{abstract}
Abstrak
Panas bumi adalah energi terbarukan dan berkelanjutan yang dapat digunakan untuk menggantikan energi fosil di masa depan. Indikasi sistem panas bumi biasanya ditandai dengan munculnya manifestasi permukaan, kehadiran mata air panas dan fumarol di kawasan Gunung Ungaran merupakan indikasi kuat potensi panas bumi bawah permukaan. Penelitian ini dilakukan untuk mengetahui energi panas bumi di bawah permukaan dan membuat model sistem panas bumi berdasarkan analisis survei geologi, geokimia dan geomagnetik. Geologi Ungaran itu sendiri disusun oleh batuan vulkanik Tersier dari Miosen sampai Pleistosen. yang diduga sumber panas di Ungaran umur Holosen. Struktur di Ungaran dikendalikan oleh patahan yang mengarah ke barat daya - timur laut, sehingga cairan dan uap dari reservoir keluar melalui zona lemah dan muncul di permukaan. Dari peta Geomagnetik yang menunjukkan tingkat magnetik rendah berkisar antara -185 sampai -3,3 nT yang ditafsirkan sebagai sumber panas di Ungaran, distribusi sumber panas meluas ke utara Gedongsongo.
\end{abstract}

Kata kunci : Gedong Songo, Panas Bumi, Magnetik

\section{Pendahuluan}

Panas bumi merupakan salah satu energi terbarukan yang diharapkan mampu mengurangi pemakaian dan ketergantungan terhadap energi fosil. Indonesia memiliki potensi besar akan keberadaan energi panasbumi, karena sesuai letaknya yang berada pada gugusan gunung api dan zona lempeng aktif dunia atau yang dikenal sebagai Ring of Fire. Oleh karena itu, di Indonesia banyak terdapat jajaran pegunungan yang menyimpan potensi panas bumi, salah satunya adalah Gunung Ungaran yang terletak di Provinsi Jawa Tengah, tepatnya berada di kabupaten Semarang dan kabupaten Kendal. Salah satu manifestasi panas bumi 
yang terdapat di Gunung Ungaran berada di daerah Gedong Songo yang terletak di lereng selatan Gunung Ungaran.

Metode geofisika yang akan dilakukan pada penelitian ini adalah metode geomagnet. Metode geomagnet, merupakan metode geofisika non-seismik yang dapat digunakan untuk menginterpretasikan lapisan bawah permukaan beserta jenis batuan berdasarkan intensitas medan magnet yang terukur di permukaan. Variasi intensitas medan magnet di permukaan yang berbeda ini menunjukkan adanya anomali magnetik, dimana anomali magnetik umumnya disebabkan karena adanya perbedaan nilai suseptibilitas pada batuan penyusun daerah tersebut. Nilai suseptibilitas merupakan nilai yang menyatakan kemampuan suatu benda atau batuan untuk dapat termagnetisasi. Pendugaan jenis batuan didasarkan pada nilai suseptibilitas magnetik yang berbeda yang dimiliki setiap batuan. Pada daerah manifestasi panas bumi umumnya ditunjukkan dengan anomali negatif dan batuan pada daerah tersebut memiliki nilai suseptibilitas yang rendah karena mengalami proses alterasi. Namun karena hasil pengukuran intensitas medan magnet di permukaan masih dipengaruhi oleh medan magnet luar dan bersifat dipole (dua kutub), maka perlu dilakukan koreksi pada data tersebut dengan melakukan koreksi variasi harian, koreksi (International Geomagnetic Reference FieId) IGRF dan untuk memudahkan proses interpretasi, maka sifat dipole nya harus dihilangkan dengan melakukan reduksi ke kutub sehingga diperoleh anomali medan magnet yang bersifat monopole. Selanjutnya dilakukan kontinuasi keatas (Upward Continuation) guna memisahkan anomali lokal dan regional. Tahapan terakhir adalah melakukan interpretasi baik secara kualitatif maupun kuantitatif (Bakye, 1995).

\section{Tinjauan Pustaka}

\subsection{Geologi Gunung Ungaran}

Gunung Ungaran merupakan gunung dengan tipe strato vulkanik yang terdiri dari batuan andesit dan basal. Produk dari bentuk strato vulkanik bersinggungan dengan formasi tersier (Budiarjo, dkk 1997). Menurut Bemmelen (1949) Gunung Ungaran selama perkembangannya mengalami ambrolan tektonik yang diakibatkan oleh pergeseran gaya berat karena dasarnya yang lemah. Gunung Ungaran tersebut memperlihatkan dua angkatan pertumbuhan yang dipisahkan oleh dua kali robohan. Ungaran pertama menghasilkan batuan andesit di Kala Pliosen Bawah, di Pliosen Tengah hasilnya lebih bersifat andesit dan berakhir dengan robohan. Daur kedua mulai di Pliosen Atas dan Holosen. Kegiatan tersebut menghasilkan daur Ungaran kedua dan ketiga. Thanden (1996) menjelaskan stratigafi dari Gunung Ungaran yang terdiri dari batuan lava andesit, lava perlitik dan breksia vulkanik selama daur Ungaran kedua dan ketiga, seperti ditunjukkan pada Gambar 1. Komposisi batuan yang terdapat di Gunung Ungaran cukup bervariasi, terdiri dari basal olivin, andesit piroksen, andesit hornblend dan gabro. Batuan ubahan dijumpai di sekitar Gedongsongo yang ditunjukkan oleh munculnya mineral-mineral halosit, kaolinit, silika amorf, kristobalit, ilit, markasit, dan pirit. Batuan ubahan tersebut terdapat dekat fumarol dan mata air panas di sepanjang aliran Sungai Item. Asosiasi kelompok mineral ubahan yang terbentuk menunjukkan temperatur bawah permukaan lapangan panasbumi Gedongsongo berkisar antara $70^{\circ}-200^{\circ} \mathrm{C}$ dan bersifat asam. 


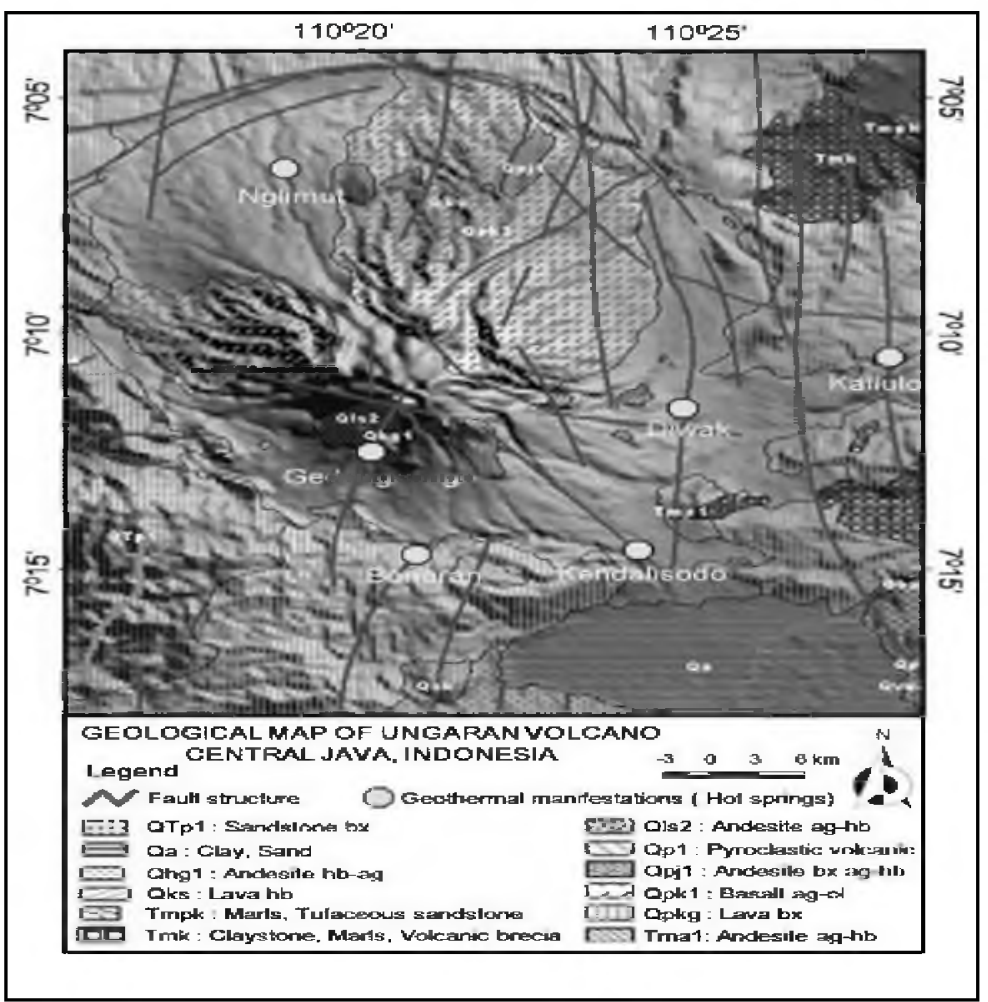

Gambar 1. Peta Geologi Ungaran modifikasi berdasarkan citra landsat TM satelit tahun 1995

Sistem panas bumi yang berkembang di Gunung Ungaran secara geologi berada di zona depresi dengan litologi permukaan didominasi oleh batuan vulkanik berumur Kuarter berupa kerucut-kerucut muda. Struktur amblesan vulkanik (depresi) yang memanjang dari barat hingga tenggara mengontrol sistem panas bumi Ungaran. Batuan vulkanik penyusun prakaldera dikontrol oleh sistem sesar yang berarah barat laut-barat daya dan tenggara-barat daya. Pada Batuan vulkanik penyusun post-kaldera hanya terdapat sedikit struktur yang dikontrol oleh sistem sesar regional (Bemmelen 1949).

\subsection{Metode Geomagnetik}

Metode geomagnetik merupakan salah satu metode geofisika yang sering digunakan untuk survei pendahuluan pada eksplorasi minyak bumi, panas bumi, batuan mineral, maupun untuk keperluan pemantauan (monitoring) gunung api. Metode ini mempunyai akurasi pengukuran yang relatif tinggi, instrument dan pengoperasian di lapangan relatif sederhana, mudah dan cepat jika dibandingkan dengan metode geofisika lainnya. Koreksi pembacaan praktis tidak perlu dilakukan.

Pada umumnya peta anomali medan magnetik (untuk geofisika terapan biasanya digunakan medan total atau medan vertikal) bersifat agak kompleks. Variasi medan lebih tak menentu dan terlokalisir sebagai akibat dari medan magnetik dipole yang merupakan besaran vektor. Peta anomali magnetik menunjukkan sejumlah besar anomali residu (sisa) yang merupakan hasil variasi yang besar bagian mineral magnetik yang terkandung dalam batuan dekat permukaan. Sebagai akibat dari hal-hal tersebut di atas, maka interpretasi yang tepat dalam metode geomagnetik relatif lebih sulit.

\subsubsection{Gaya Magnetik}

Dasar dari metode magnetik adalah gaya Coulomb antara dua kutub magnetik $m_{1}$ dan $m_{2}$ (e.m.u) yang berjarak $r(\mathrm{~cm})$ dalam bentuk: 


$$
\vec{F}=\frac{m_{1} m_{2}}{\mu_{0} r^{2}} \vec{r} \quad \text { (dyne) (Persamaan1) }
$$

dengan $\mu_{0}$ adalah permeabilitas medium dalam ruang hampa, tidak berdimensi dan berharga satu (Telford, 1990).

\subsubsection{Kuat Medan Magnet}

Kuat medan magnet ( $\vec{H}$ ) pada suatu titik yang berjarak $r$ dari $m_{1}$ didefinisikan sebagai gaya per satuan kuat kutub magnet, dapat dituliskan dalam persamaan berikut :

$$
\vec{H}=\frac{\vec{F}}{m_{2}}=\frac{m_{1}}{\mu_{0} r^{2}} \vec{r} \quad \text { (Oersted) } \quad \text { (Persamaan 2) }
$$

\section{Metode Penelitian}

Data magnetik yang digunakan adalah data primer yang telah dilakukan koreksi variasi harian, dan koreksi IGRF diperoleh dari hasil pengukuran pada lereng selatan sekitar manifestasi panas bumi Gedong Songo Gunung Ungaran. Pada lereng selatan jumlah data yang terukur dan digunakan sebanyak 40 titik pada kordinat $9200714^{\circ} \mathrm{LS}-9203973^{\circ} \mathrm{LS}$ dan $425896^{\circ} \mathrm{BT}-428469^{\circ} \mathrm{BT}$, dielevasi 965.5 meter hingga 1552.3 meter. Kemudian data anomali yang telah dikoreksi tersebut dijadikan masukan pembuatan kontur anomali medan magnet total. Tahap-tahap yang dilakukan pada penelitian ini adalah :

a. Membuat peta kontur anomali medan magnet total berdasarkan data daerah penelitian yang telah dilakukan koreksi IGRF dan koreksi variasi harian.

b. Melakukan reduksi ke kutub terhadap peta kontur anomali medan magnet total, untuk merubah sifatnya yang dipole menjadi monopole.

c. Melakukan transformasi kontinuasi ke atas sebesar 2000 meter untuk memisahkan anomali medan magnet regional dan anomali medan magnet residual.

d. Melakukan filter horizontal gradient dan vertical gradient pada anomali medan magnet total yang masih bersifat dipole untuk menganalisa keberadaan sesar atau batas kontak antar batuan.

e. Menginterpretasikan peta kontur anomali medan magnet residual secara kualitatif dengan menganalisa respon dari klosur-klosur anomali yang muncul.

\section{Hasil dan Pembahasan}

Daerah penelitian berada di daerah gunung Unguran dan sekitarnya. Morfologi Gunung Ungaran dapat dibagi menjadi beberapa morfologi utama yaitu morfologi Gunung Ungaran Tua, morfologi Gunung Ungaran Muda (daerah puncak, lereng dan loki) kerucut gunung api dan dataran Alluvial. Syabaruddin (2003).

Struktur geologi yang berkembang di daerah Gunung Ungaran dan sekitarnya sebagian besar berupa sesar turun dan kekar. Sesar turun Ringin terbentuk akibat runtuhan tubuh Gunung Ungaran Tua yang terjadi karena proses volcano tectonic depression. Sesar yang lain Sesar Gintungan. Sesar turun ini berarah barat laut tenggara yang memisahkan Gunung Gendol dengan Gunung Lapak. Sesar Gongso, Sesar turun ini terbentuk akibat proses longsoran tubuh gunung api keamh barat daya yang memotong sesar Gintungan. Scsar Tarukan, Sesar ini dihasilkan dari proses longsoran kearah selatan yang memotong sesar Gongso. Di lapangan dapat diamati berupa kenarnpakan adanya brmk morfologi yang tajam antara bagian footwall dengan hanging wall. Pada rekahan akibat longsoran menghasilkan alur sungai yang dalam dan terjal. Sesar Panjang. Sesar ini juga terbentuk akibat proses longsoran yang memotong sesar Tarukan. Terdapat gawir sesar yang terjal dan bukit yang ada dibawah gawir tersebut terlihat memanjang kearah selatan. Pada bidang sesar tersebut 
dijumpai adanya pemunculan manifestasi panas bumi yang berupa mata air panas, fumarol, mud pot steaming ground, kolam air hangat, mata air biasa dan batuan yang mengalami alterasi (Gambar 2).

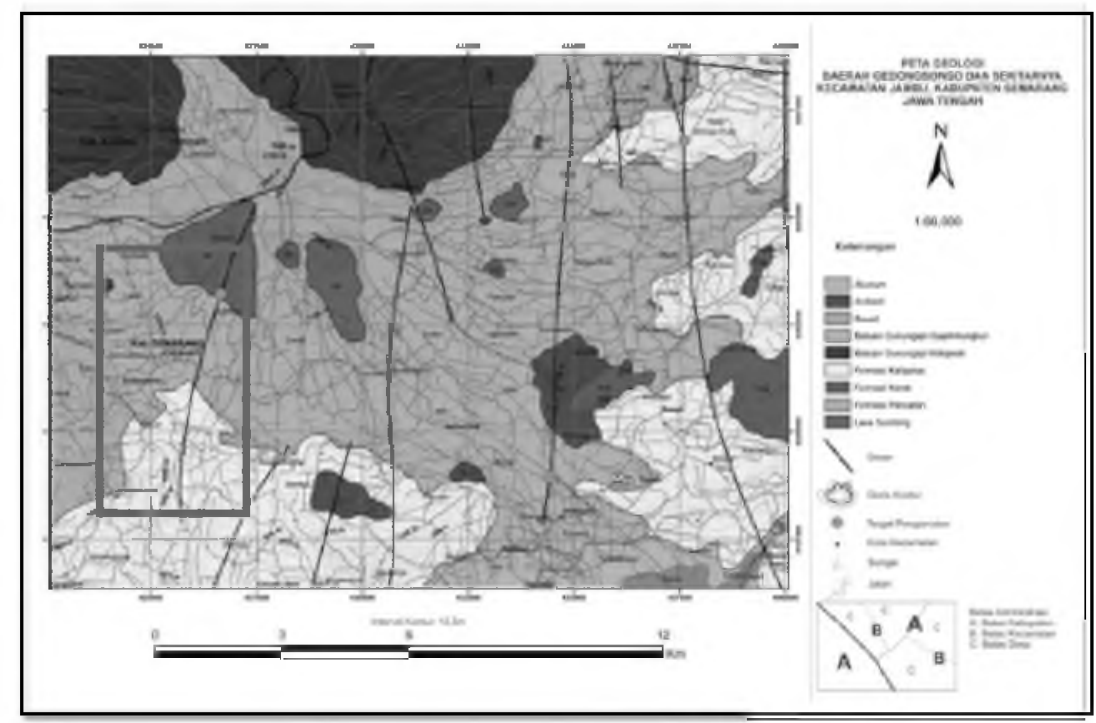

Gambar 2. Peta Geologi Regional Daerah Ungaran dan Sekitarnya

Peta kontur anomali medan magnet total adalah peta nilai intensitas medan magnet terukur disuatu titik yang dihasilkan oleh batuan dibawah permukaan yang menjadi target pengukuran magnetik. Peta kontur anomali medan magnet total diperoleh setelah melakukan koreksi variasi harian dan koreksi IGRF pada data pengukuran intensitas medan magnet di lapangan. Peta kontur anomali medan magnet total untuk lereng selatan Gunung Ungaran ditampilkan pada Gambar 3.

Dari peta anomaly magnetic reduce to pole (Gambar 3) menunjukkan bentuk reserovar dari geothermal gunung Ungaran. Kemudian dilakukan pembuatan Total Magnetik Intensity (Gambar 4).

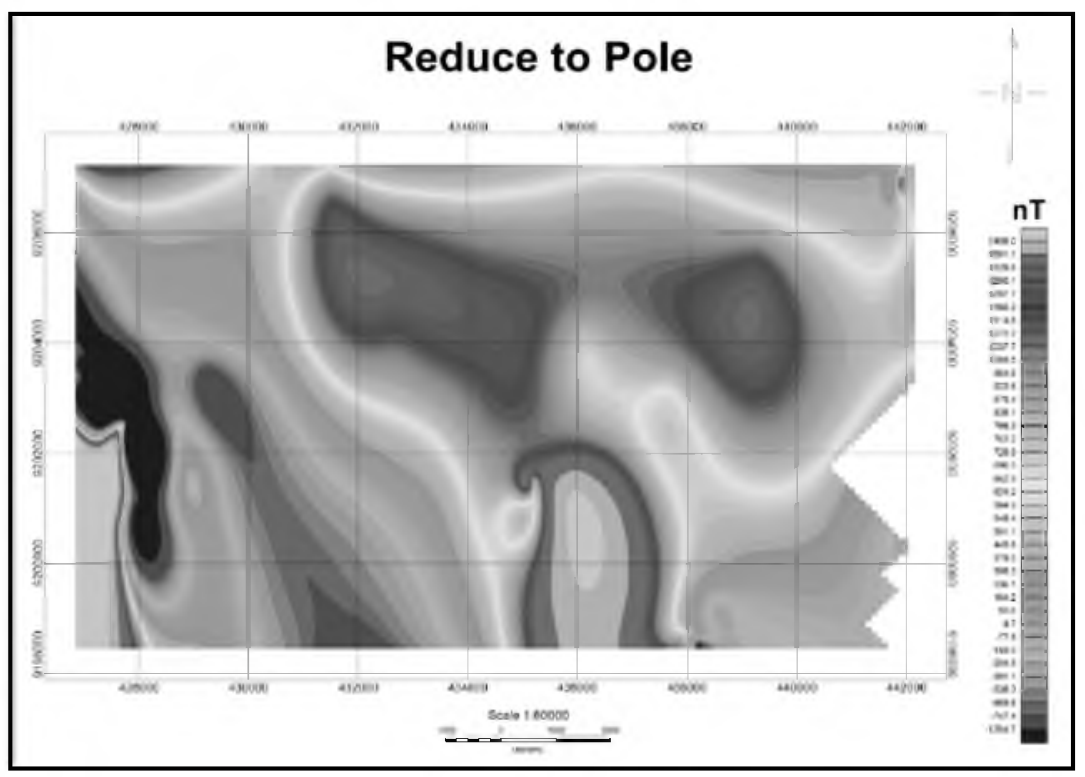

Gambar 3. Peta Reduce to Pole gunung Ungaran dan sekitarnya 


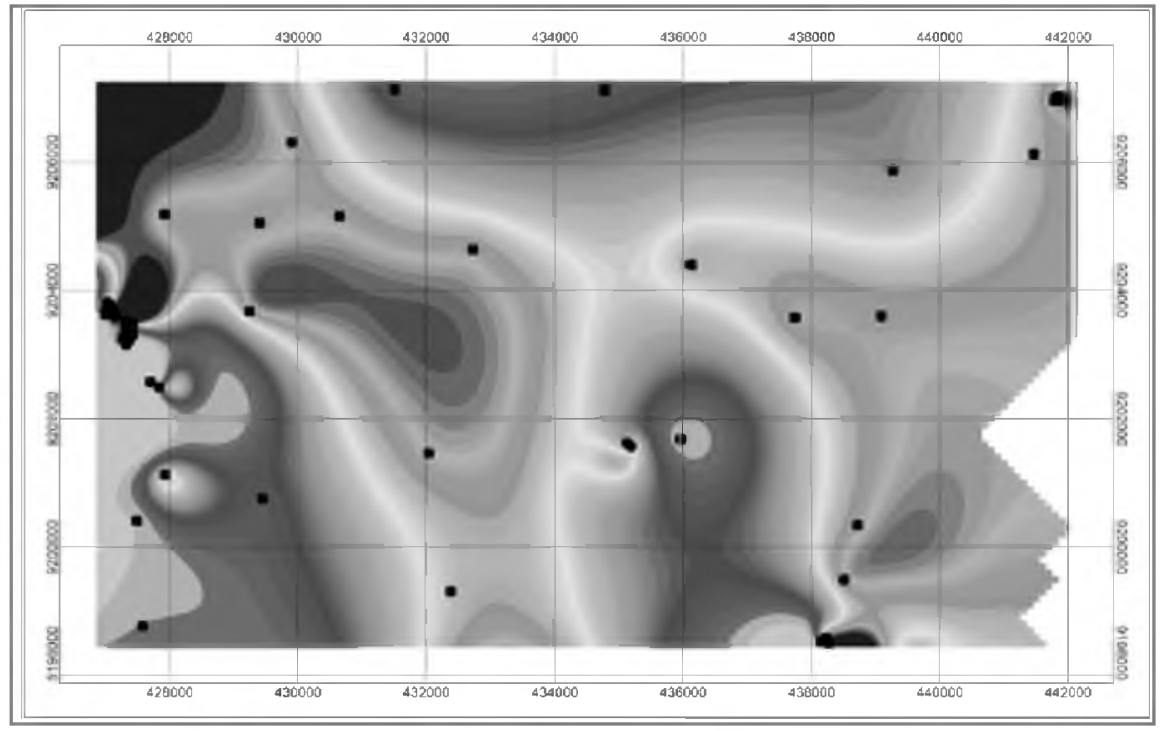

Gambar 4. Peta Total Magnetic Intensity gunung Ungaran dan sekitarnya

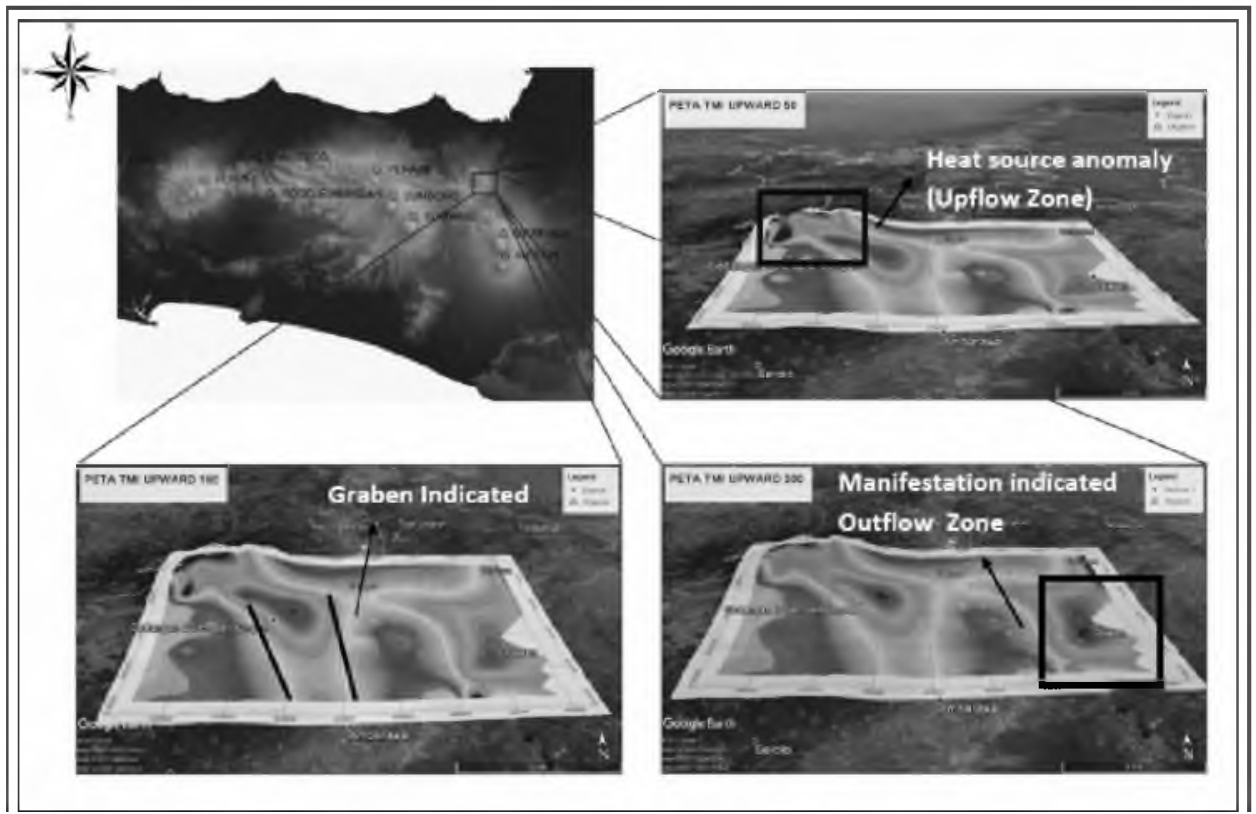

Gambar 5. Manifestasi Panas bumi area Gedong Songo dari magnetik dan digabungkan dengan Google Earth

Pada indeks warna merah menyebar ke arah utara peta dengan nilai mulai dari 388,3 sampai $1535,8 \mathrm{nT}$ dapat diartikan sebagai batuan vulkanik kaligesik, ini juga mengacu pada geologi daerah penelitian, formasi batuan ditemukan adanya batuan vulkanik yang memiliki banyak Kandungan mineral Parmagnetics seperti piroksen, ampibol, biotit sehingga memiliki nilai respon magnetik tinggi. Di bagian barat daya peta juga memiliki nilai magnetisme yang tinggi, respon bernilai tinggi ini didapat dari adanya lahar sumbing pada titik tersebut sehingga memiliki nilai magnet yang tinggi akibat mineral feromagnetik. Sedangkan di sebelah selatan 
peta memiliki nilai yang tinggi pula, mengacu pada geologi dan singkapan regional yang ditemui respon magnetisme tinggi akibar adanya litologi batuan andesit, karena andesit merupakan zat beku batuan beku Fe yang unsurnya cukup tinggi sehingga Respon juga daya tariknya tinggi.

Pada skala warna hijau-kuning dengan nilai berkisar antara 9 sampai 274,7 nT yang tersebar di tengah dan timur peta dapat diartikan sebagai batuan vulkanik dari gunung api gajahmungkur dan batuan sedimen dari pembentukan kaligetas, karena didominasi oleh batuan sedimen yang dihasilkan. Dari pelapukan batuan sebelumnya, nilai magnetisme sedang, karena lebih didominasi mineral klastik silky. Namun, di sebelah timur peta, ini menunjukkan adanya kesalahan berorientasi utara, hal ini terlihat dari pola geologi dan degradasi regional nilai magnetik yang tiba-tiba menjadi negatif pada koordinat 438000 : 9198000 (gambar 5). Adanya gesekan antara dua blok batuan yang mengalami operasi caesar akan menyebabkan panas dan deformasi sepanjang medan patahan dimana keduanya akan mengakibatkan saat dipol magnetik menjadi rendah karena bersifat acak lagi, seperti batang magnet yang dimangsa kemudian menjadi magnetisme. Akan rendah.

Pada skala biru dengan nilai berkisar antara -185 sampai -3,3 nT menyebar relatif terhadap pusat dan barat laut peta. Di tengah jika mengacu pada geologi regional yang diapit oleh dua kesalahan besar yang berorientasi ke utara-selatan, Jika dilihat dari pola anomali yang terbentuk menunjukkan tingkat magnetik rendah di daerah melebar dan memanjang dalam skala besar, menimbulkan kemungkinan adanya struktur graben. Akibat diapit oleh dua kesalahan tersebut, kehadiran graben terbentuk akibat anomali karena kesalahan yang seharusnya hanya ada disekitar bidang sesar yang melebar. Sedangkan di sebelah barat laut peta ada penutupan warna biru yang sangat rendah, koordinat lokasi ini juga ditemukan beberapa manifestasi seperti fumarol dan tampilan bidang kesalahan. Dari pengukuran orientasi struktur di lapangan diketahui bahwa kesalahan pada lokasi ini adalah kesalahan horisontal. Kesalahan ini diduga menjadi jalur utama manifestasi panas bumi di daerah tersebut. Tekanan terus menerus dari reservoir panas bumi mengarah pada pembentukan fraktur yang kemudian berkembang menjadi kesalahan, karena pembentukan kesalahan dimulai dengan banyak zona lemah yang bocor sehingga uap dan cairan panas dapat menembus melalui fraktur zona lemah yang menyebabkan pembentukan Perubahan (Argilicadvance argilic) pada dinding samping melewati cairan dan kemudian uap dan permukaan cairan panas sebagai manifestasi. Hal ini menyebabkan situs tersebut merespons nilai magnetisme yang sangat rendah, adanya batuan beku (sumber heatsource harus memiliki nilai magnetisme yang besar) menjalani proses yang disebut badan demagnetisasi (termasuk pencucian, penggantian) dan mengakibatkan perubahan fisik mineral dari mineral. Andesitik terhadap hidrotermal mineral, proses ini mempengaruhi perubahan sifat fisik batuan seperti kerapatan porositas, resistivitas, konduktivitas, dan kerentanan batuan yang sangat rendah.

\section{Kesimpulan dan Saran}

Berdasarkan kondisi litologi yang digambarkan di fasia vulkanik gunung Ungaran dan struktur sekarang dan pencitraan bawah permukaan geomagnetik, dapat digambarkan sistem panas bumi berikut gunung Ungaran :

A). Reservoar

Ini terdiri dari batuan vulkanik yang memiliki porositas primer sebagai hasil pelepasan gas selama proses pendinginan (vesikula), sedangkan deposit piroklastik yang ada di area studi menunjukkan tekstur yang didukung biji-bijian dengan blok fragmen yang retak atau dikenal sebagai retakan jigsaw, yang memungkinkan Untuk porositas yang baik. 
B). Batuan Tudung atau Cap Rock

Dilihat dari fasies di daerah Gedongsongo terdiri dari fasies sentral Ungaran Muda berupa aliran lava dan aliran deposito piroklastik. Endapan tersebut telah mengalami alterasi argilik yang ditemukan di daerah penelitian, yang memiliki nilai porositas dan permeabilitas rendah karena terumbu porositas batu dengan adanya mineral tanah liat dan menyebabkan kerak kedap dan sesuai.

C). Sumber Panas

Komposisi magma yang merupakan sumber panas Gunung Ungaran memiliki komposisi andesitik, mengacu pada pengamatan beberapa sayatan tipis sampel batuan yang menunjukkan batuan lebih berlumpur pada andesit hornblende dan andesit piroksen. Sementara analisis geomagnetik menunjukkan bahwa sumber panas berada di barat laut peta dengan tingkat magnetik rendah, yang berarti tepat di bawah manifestasi Gedongsongo.

D). Recharge Area

Perbedaan morfologi yang ada di selatan menunjukkan bahwa daerah resapan sistem panas bumi Gedongsongo dan daerah pemetaan sekitarnya terletak di wilayah selatan, yaitu di daerah Lanjan, Berokan dan Banyukuning.

\section{Daftar Pustaka}

Bemmelen,V.R.W., 1949, The Geology of Indonesia. The Hague Martinus Nijnhoff, Vol. IA. Budiardjo, Nugroho, dan Budihardi., 1997, Resources characteristic of the Ungara field, Central Java, Indonesia. Proceedings of the Nationalseminar of Human Resources Indonesian Geologist, Geological Engineering Mineral Tecnology Faculty, UPN "Veteran", Yogyakarta, pp. 139-147.

Boko, Wahyudi, dan Imam Suyanto. 2003, Analisis Data Magnetik Untuk Mengetahui Struktur Bawah Permukaan Daerah Manifestasi Air Panas di Lereng Utara Gunung Api Ungaran, Program Studi Geofisika Fakultas Matematika dan Ilmu Pengetahuan Alam Universitas Gajah Mada, Yogyakarta.

Blakely, R.J., 1995, Potential Theory in Gravity and Magnetic Applications, Cambridge University Press, NewYork.

Prasetyo, Bagus, B., 2012, Identifikasi Struktur Bawah Permukaan Menggunakan Metode Geolistrik Konfigurasi Schlumberger di Area Mantfestasi Geothermal Gedong Songo Lereng Selatan Gunung Ungaran, Jurusan Fisika Fakultas Matematika dan Ilmu Pengetahuan Alam Universitas Diponegoro, Semarang.

Tarmidzi, F., 2013, Aplikasi Metode Bidimensional Empirical Mode Decomposition (BEMD) Untuk Data Gaya Berat Gunung Ungaran Indonesia. Jurusan Fisika Fakultas Sains dan Matematika Universitas Diponegoro, Semarang.

Telford, W.M., Geldart, L.P. dan Sheriff, R.E, 1990, Applied Geophysics, second edition, Cambridge University Press, London.

Thanden RE, Sumadirdja H, Richard PW, Sutisna K. dan Amin TC., 1996, Peta Geologi Regional Lember Magelang dan Semarang, skala 1: 100.000, Pusat Penelitian dan Pengembangan Geologi, Bandung.

Setyawan, A., Fujimitsu, Y., Fukuoka, K., Nishijima, J., Ehara, S., Saibi, H., 2007, Geophysical Investigation of Ungaran Volcavo, Central Java, Indonesia, Proceedings 29th, New Zeland.

Setyawan, A., Ehara, S., Fujimitsu, Y., Nishijima, J., Saibi, H., Aboud, E., 2009, The gravity anomaly of Ungaran Volcano, Indonesia: analysis and interpretation, vol.31., No.2., J. Geotherm, Res.Soc., Japan 